\title{
Chemical vapour treatment for enhancing the surface finish of PLA object produced by fused deposition method using the Taguchi optimization method
}

\author{
Subham Sekhar Panda ${ }^{1} \cdot$ Rimpy Chabra $^{1} \cdot$ Sajan Kapil ${ }^{2} \cdot$ Virendra Patel $^{1}$
}

Received: 19 October 2019 / Accepted: 10 April 2020 / Published online: 16 April 2020

(c) Springer Nature Switzerland AG 2020

\begin{abstract}
In this study, the effect of process parameter and various post-processing techniques on surface roughness of PLA object produced by fused deposition method is investigated. The economical and versatile method with the proper design of the experiments to reduce the surface roughness is our objective. The PLA is selected as the workpiece material, a biodegradable material which is vastly used in medical implants, where surface roughness is a major issue. The various post-processing technique is analyzed, and the parameter optimization is taken into consideration. Post-processing technique like chemical treatment, vapour smoothing, sanding and polishing is carried out. Taguchi design of the experiment is also used to optimize the parameter that affects the targeted surface roughness. Taguchi $L_{g}$ orthogonal array is used to organize the different parameters, and Minitab software is used to determine the optimum parameter setting. The dichloromethane chemical is found to be the best chemical for dissolving the PLA material and reducing the layer lines so that the surface roughness can be reduced. The final results confirmed that the chemical vapour treatment using dichloromethane and the Taguchi method sufficient to improve the surface roughness.
\end{abstract}

Keywords Fused deposition method · Taguchi optimisation · Chemical vapour treatment · Poly lactic acid

\begin{tabular}{|c|c|}
\hline \multicolumn{2}{|c|}{ Abbreviations } \\
\hline FDM & Fused deposition modelling \\
\hline ITER & $\begin{array}{l}\text { International thermonuclear experimental } \\
\text { reactor }\end{array}$ \\
\hline CTTC & Central tool room and training centre \\
\hline CAD & Computer-aided design \\
\hline $\mathrm{S} / \mathrm{N}$ & Signal to noise ratio \\
\hline ANOVA & Analysis of variance \\
\hline PLA & Poly lactic acid \\
\hline ABS & Acrylonitrile butadiene styrene \\
\hline DCM & Dichloromethane \\
\hline
\end{tabular}

\section{Introduction}

In recent years, global markets have led to a fundamental change in product development. The improvement of products with the highest quality and lowest cost and their production in the shortest time at a reasonable price, within limits of safety and other criteria, are necessary to remain competitive in global manufacturing. An essential part of product development is the engineering design process, which begins by identifying a need and concludes with a ready-to-manufacture prototype [1].

Today it is very predominant to guide a product from concept to market rapidly and inexpensively. The viewpoint of industries has changed from traditional product development methodology to rapid prototyping

$\triangle$ Rimpy Chabra, rimpychabra@soa.ac.in | 1 Department of Mechanical Engineering, Institute of Technical Education and Research, Siksha O Anusandhan (Deemed to be University), Khandagiri, Bhubaneswar, Odisha 75103, India. ${ }^{2}$ Department of Mechanical Engineering, Indian Institute of Technology Guwahati, Guwahati, Assam, India. 
techniques because rapid prototyping and manufacturing techniques have shown a high potential to reduce the cycle time and cost of product development [2]. Rapid prototyping or additive manufacturing is a method to make these prototypes much more accessible, quicker and also more economical (cost-effective) [3]. Rapid prototyping is the next frontier for researchers, publishers and users of advanced technologies. 3D printing using FDM/layer deposition is one of the emerging technologies at the global level [4-7]. The FDM should be optimized like levelling the bed, checking for the nozzle blockage and extra molten material on nozzle tip. The printing parameter is given through a printing software which allows user to change its specifications like layer thickness, print speed, nozzle flow, outer and inner wall speed, printing temperature, application of cooling fan etc., according to the product demand. Various works have been done to optimize the process parameters to reduce surface roughness [8-12]. Post-processing of FDM [13-18] parts is very necessary because layer lines are generally present in the surface of FDM parts. These layer lines are responsible for surface roughness which are produced by staircase effect. Nowadays, a product with a supreme surface finished is a much-demanded specification because an object with best surface texture makes it more valuable and demanding.

Hence, keeping an eye on enhancing surface finish post-processing is carried out in our research work using chemical treatment, optimizing the process parameter, vapour smoothing and other reliable post-processing technique.

\section{Experimental setup and investigation}

Today it is indispensable to produce dimensionally accurate as well as mirror-finished object. So that in the product development stage, the process of post-processing is vital in the 3D printing department. Various techniques are there in the market to produce high surface finish, but in the case of PLA material, the techniques complicated and time-consuming [19-21].

For the 1st phase of our experiment, the sample specimens are produced with the recommended setting in the ITER lab for study purpose. In the 2nd phase of our experiment, the sample specimens are produced with the recommended setting, which is to undergo various postprocessing techniques. In the 3rd phase, the samples are produced in CTTC lab with the custom setup with varying the printing parameter with the help of the Taguchi method of the experiment to find the optimum parameter setting for printing.

\section{SN Applied Sciences}

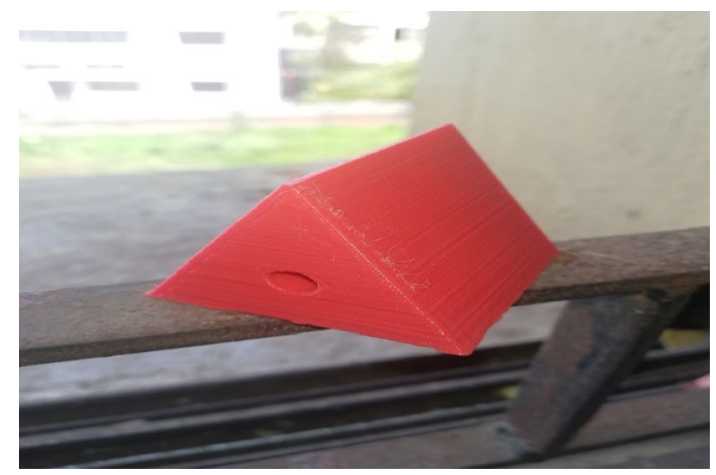

Fig. 1 Sample specimen of FDM

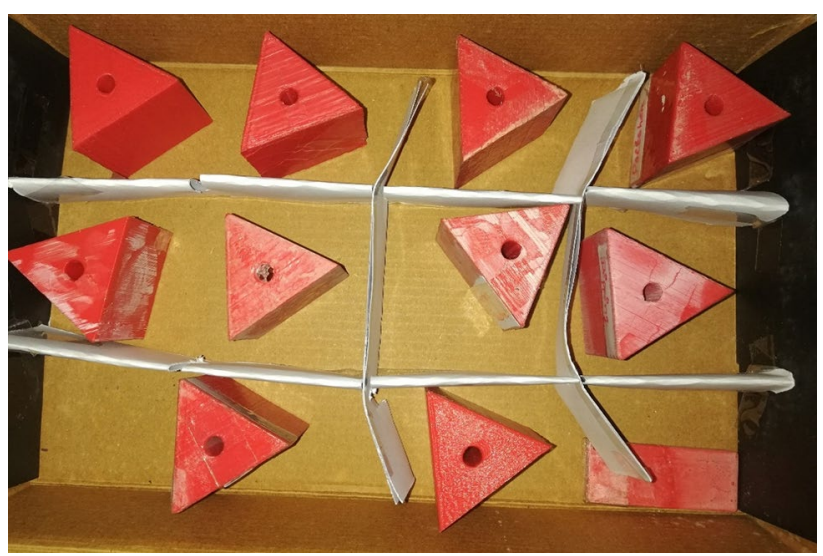

Fig. 2 Sample for post processing

\subsection{Analysis of printed object}

First, the 3D model is created in SolidWorks software. Then the 3D CAD model is converted into FDM printing format and then using CURA software the 3D printing is done using an FDM machine $[22,23]$. The Fig. 1 shows the fused deposition modelling along with the samples produced in the $1 \mathrm{st}$ phase. The dimension of that specimen is $5 \mathrm{~cm} \times 5 \mathrm{~cm} \times 5 \mathrm{~cm}$ (length $=5 \mathrm{~cm}$, breath $=5 \mathrm{~cm}$, height $=5 \mathrm{~cm}$ ).

\subsection{Sample generation for post processing techniques}

After producing the 1st phase of the sample's parts, we go for the 2 nd phase of our experiment that is the generation of sample object for our post-processing experiment. Figure 2 shows the samples for post processing. The dimension of the 20 specimens was same i.e. $5 \mathrm{~cm} \times 5 \mathrm{~cm} \times 5 \mathrm{~cm}$ (length $=5 \mathrm{~cm}$, breath $=5 \mathrm{~cm}$, height $=5 \mathrm{~cm}$ ). 


\subsection{Post processing techniques}

The 20 samples after printing from FDM machine treated with different post-processing techniques to find out which technique is able to melt down those layers line in the inclined surface. The post-processing of those parts along with the pictorial view described below.

\subsubsection{Chemical treatment}

The chemical treatment is carried out in a chemistry laboratory in ITER chemistry department. The chemical used during the experiment is bought from a government registered chemical shop with $100 \%$ concentration. Those chemicals come with a seal-tight plastic container with a lid. Chemical treatment is done in two different way, i.e. spraying method and dipping method. In the spray method, the sample specimen is placed on the glass plate in such a way so that two surfaces are inclined. These inclined surface are used for treatment. Acetone with $100 \%$ concentration is sprayed on the surface of the prism. In the dipping method, the whole specimen is dipped under the chemical for 1-2 min, and the observation is noted. The concentration of the chemical was $100 \%$. After the operation, the sample is kept under sunlight for drying. Then the sample was undergone detection of microstructure and surface roughness.

2.3.1.1 Acetone treatment Acetone is the organic compound with the formula $\left(\mathrm{CH}_{3}\right)_{2} \mathrm{CO}$. It is a colourless, volatile, flammable liquid. It is one of the best-known postprocessing chemicals for ABS material. Here, it is used for checking whether it works for PLA or not. Figure 3a shows the post-processing treatment of acetone (Table 1).

2.3.1.2 Ethyl acetate treatment Ethyl acetate is the organic compound with the formula $\mathrm{C}_{4} \mathrm{H}_{8} \mathrm{O}_{2}$. This colourless liquid has a characteristic sweet smell and is used in glues, nail polish removers, decaffeinating tea and coffee. Ethyl acetate is used primarily as a solvent and dilu-

Table 1 Properties of acetone

\begin{tabular}{ll}
\hline Properties & Value \\
\hline Molecular formula & $\left(\mathrm{CH}_{3}\right)_{2} \mathrm{CO}, \mathrm{C}_{3} \mathrm{H}_{6} \mathrm{O}$ \\
Molar mass & $58.08 \mathrm{~g} / \mathrm{mol}$ \\
Appearance & Colourless liquid \\
Density & $0.7925 \mathrm{~g} / \mathrm{cc}$ \\
Melting point & $-94.9^{\circ} \mathrm{C}$ \\
Boiling point & $56.53^{\circ} \mathrm{C}$ \\
\hline
\end{tabular}
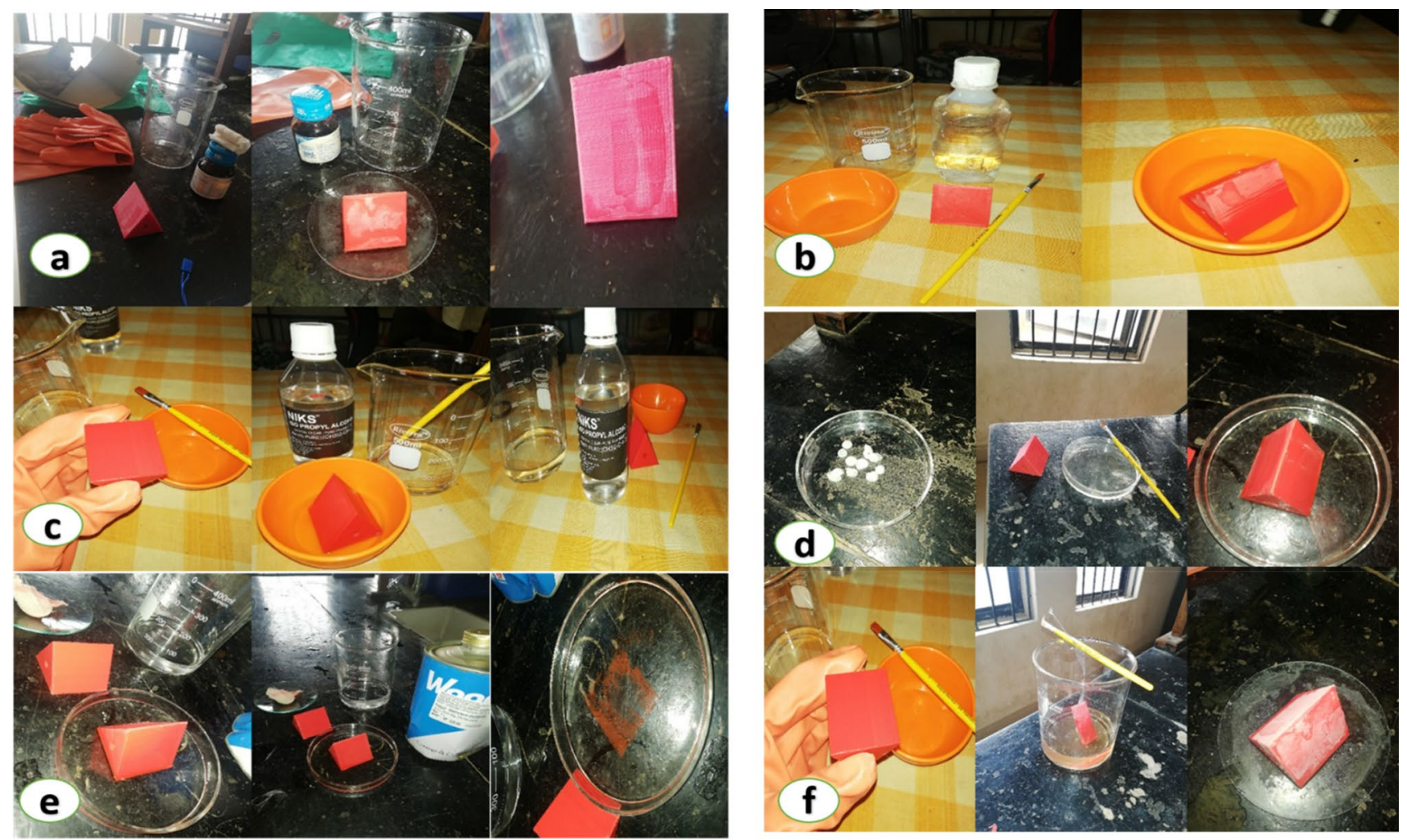

Fig. 3 Post-processing treatment $\mathbf{a}$ acetone, $\mathbf{b}$ ethyl acetate, $\mathbf{c}$ isopropyl alcohol, $\mathbf{d}$ sodium hydroxide, e dichloromethane, $\mathbf{f}$ tetrahydrofuran 
Table 2 Properties of ethyl acetate

\begin{tabular}{ll}
\hline Properties & Value \\
\hline Molecular formula & $\mathrm{C}_{4} \mathrm{H}_{8} \mathrm{O}_{2}$ \\
Molar mass & $88.11 \mathrm{~g} / \mathrm{mol}$ \\
Appearance & Colourless liquid \\
Density & $902 \mathrm{~kg} / \mathrm{m}^{3}$ \\
Melting point & $-83.6^{\circ} \mathrm{C}$ \\
Boiling point & $77^{\circ} \mathrm{C}$ \\
\hline
\end{tabular}

Table 3 Properties of isopropyl alcohol

\begin{tabular}{ll}
\hline Properties & Value \\
\hline Molecular formula & $\mathrm{CH}_{3} \mathrm{CHOHCH}_{3}, \mathrm{C}_{3} \mathrm{H}_{8} \mathrm{O}$ \\
Molar mass & $60.096 \mathrm{~g} / \mathrm{mol}$ \\
Appearance & Colourless liquid \\
Density & $0.786 \mathrm{~g} / \mathrm{cm}^{3}$ \\
Melting point & $-89^{\circ} \mathrm{C}$ \\
Boiling point & $82.6^{\circ} \mathrm{C}$ \\
\hline
\end{tabular}

ent, being favoured because of its low cost, low toxicity, and agreeable odour. After reading various Journal, this can be our next choice of experiment with. The post-processing treatment with ethyl acetate has been shown in Fig. 3b (Table 2).

2.3.1.3 Isopropyl alcohol treatment Isopropyl alcohol or isopropanol is a chemical compound with a chemical formula $\mathrm{CH}_{3} \mathrm{CHOHCH}_{3}$. Its flammable chemical compound with a strong odour and colourless. It is used in the manufacture of a wide variety of industrial and household chemicals. It is a common ingredient in chemicals such as antiseptics, disinfectants and detergents. Isopropyl alcohol is dissolved in water, ethanol, ether, and chloroform. It is mostly used as a solvent as a coating in many industries, so it is used in our experiment. The post-processing treatment with isopropyl alcohol has been shown in Fig. $3 \mathrm{c}$ (Table 3).

2.3.1.4 Sodium hydroxide treatment Sodium hydroxide or know as caustic soda is an inorganic compound with the formula $\mathrm{NaOH}$. It is highly soluble in water. It is used in various industry like soap, paper, textiles, detergents etc. Due to its chemical pulping nature, it is used in our experiments. It can also dissolve amphoteric metals and compounds where $\mathrm{NaOH}$ is acting as alkaline solution which removes anodizing or converting a polished surface to satin-like finish. Due to its caustic nature, it acts as a cleaning agent which dissolve grease, oils, fats and protein-based deposits. The post-processing treatment with sodium hydroxide has been shown in Fig. 3d (Table 4).
Table 4 Properties of sodium hydroxide

\begin{tabular}{ll}
\hline Properties & Value \\
\hline Molecular formula & $\mathrm{NaOH}$ \\
Molar mass & $39.9971 \mathrm{~g} / \mathrm{mol}$ \\
Appearance & White, waxy, \\
& opaque \\
& crystals \\
Density & $2.13 \mathrm{~g} / \mathrm{cm}^{3}$ \\
Melting point & $318^{\circ} \mathrm{C}$ \\
Boiling point & $1388^{\circ} \mathrm{C}$ \\
\hline
\end{tabular}

Table 5 Properties of dichloromethane

\begin{tabular}{ll}
\hline Properties & Value \\
\hline Molecular formula & $\mathrm{CH}_{2} \mathrm{Cl}_{2}$ \\
Molar mass & $84.93 \mathrm{~g} / \mathrm{mol}$ \\
Appearance & Colourless liquid \\
Density & $1.3266 \mathrm{~g} / \mathrm{cm}^{3}$ \\
Melting point & $-96.7{ }^{\circ} \mathrm{C}$ \\
Boiling point & $39.6{ }^{\circ} \mathrm{C}$ \\
\hline
\end{tabular}

2.3.1.5 Dichloromethane treatment Dichloromethane is an organic compound with formula $\mathrm{CH}_{2} \mathrm{Cl}_{2}$. This colourless, volatile liquid with a moderately sweet aroma is widely used as a solvent. Although it is not miscible with water, it is polar and miscible with many organic solvents. DCM's volatility and ability to dissolve a wide range of organic compounds makes it a useful solvent for many chemical processes. Due to its dissolving nature is used in our experiments to determine its dissolving potential of the chemical. The post-processing treatment with dichloromethane has been shown in Fig. 3e (Table 5).

2.3.1.6 Tetrahydrofuran treatment Tetrahydrofuran is an organic compound with having formula $\left(\mathrm{CH}_{2}\right)_{4} \mathrm{O}$. It is a colourless, water-miscible organic liquid with low viscosity. It is mainly used as a precursor to polymers. It is having a property of acting as a solvent which can dissolve many non-polar and polar chemical compound so that it is used in our experiment. The post-processing treatment with tetrahydrofuran has been shown in Fig. $3 f$ (Table 6).

After completing of various chemical treatment using 6 different chemicals, we go for the surface roughness test by Taylor and Hobson surface roughness tester. The results are summarised in Table 10 from the result it can be observed that the dichloromethane is more capable of dissolving the PLA material in comparison to other used chemicals. So, the next treatments are done using dichloromethane as the primary chemical. After this, we go for 
Table 6 Properties of tetrahydrofuran

\begin{tabular}{ll}
\hline Properties & Value \\
\hline Molecular formula & $\left(\mathrm{CH}_{2}\right)_{4} \mathrm{O}$ \\
Molar mass & $72.107 \mathrm{~g} / \mathrm{mol}$ \\
Appearance & Colourless liquid \\
Density & $0.8892 \mathrm{~g} / \mathrm{cm}^{3}$ \\
Melting point & $-108.4{ }^{\circ} \mathrm{C}$ \\
Boiling point & $66^{\circ} \mathrm{C}$ \\
\hline
\end{tabular}

vapour treatment and post-processing using san paper and polisher as an add-on to our experiment.

\subsubsection{Post processing using dichloromethane and sandpaper}

Sandpaper is used to grind extra material present on the rough surface. In our experiment, the layer lines which are present in the surface of the specimen is ground by using different grade sandpaper, then the change in the value of surface roughness is measured under the surface roughness tester. The sandpaper used in our experiment is industry-standard, having grade 500 microns, 1000 micron and 1500 micron. After the DCM chemical treatment is over the treatment object is smoothly rubbed on the surface of the object till the roughness reduced (Fig. 4).

\subsubsection{Post processing using dichloromethane and transparent vinyl polisher}

A new approach is made to determine how polisher is beneficial in our case to achieve an excellent surface finish. After the chemical treatment overusing dichloromethane, the vinyl polisher is used to polish on the surface of the object so that the change in the surface roughness is measured (Fig. 5).

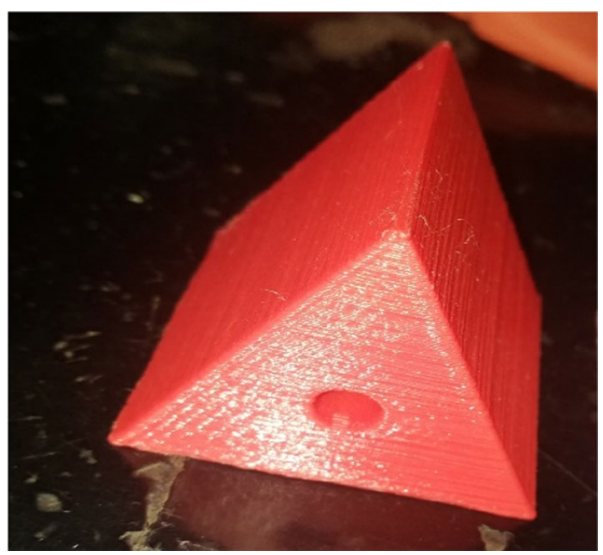

Fig. 5 Post-processing using DCM and polisher

\subsubsection{Vapour smoothing treatment}

Vapour treatment is a technique used for smoothing surface roughness by using the substance in vapour form. In our experiment after chemical treatment is over the same chemical used in the experiment again used with a vapour smoothing technique to determine the change in surface roughness. In this process, the hot plate machine is used to heat the chemical to a specific limit than by using the vapours of that chemical the treatment is done.

2.3.4.1 Vapour treatment with dichloromethane Dichloromethane is used in the treatment because, in our previous treatment, this chemically substantially reduced the layer lines in comparison to other chemicals. The dichloromethane is heated up to $60^{\circ} \mathrm{C}$. At this temperature, dichloromethane started boiling because the boiling point temperature of this chemical is $39.6^{\circ} \mathrm{C}$. Using the vapour of this chemical, the post-processing is done. The specimen is kept under the vapour for about $5 \mathrm{~min}$, $10 \mathrm{~min}, 15 \mathrm{~min}$ respectively, and the result is noted. The change in surface texture is measured in surface rough-
Fig. 4 Post-processing using DCM and sandpaper
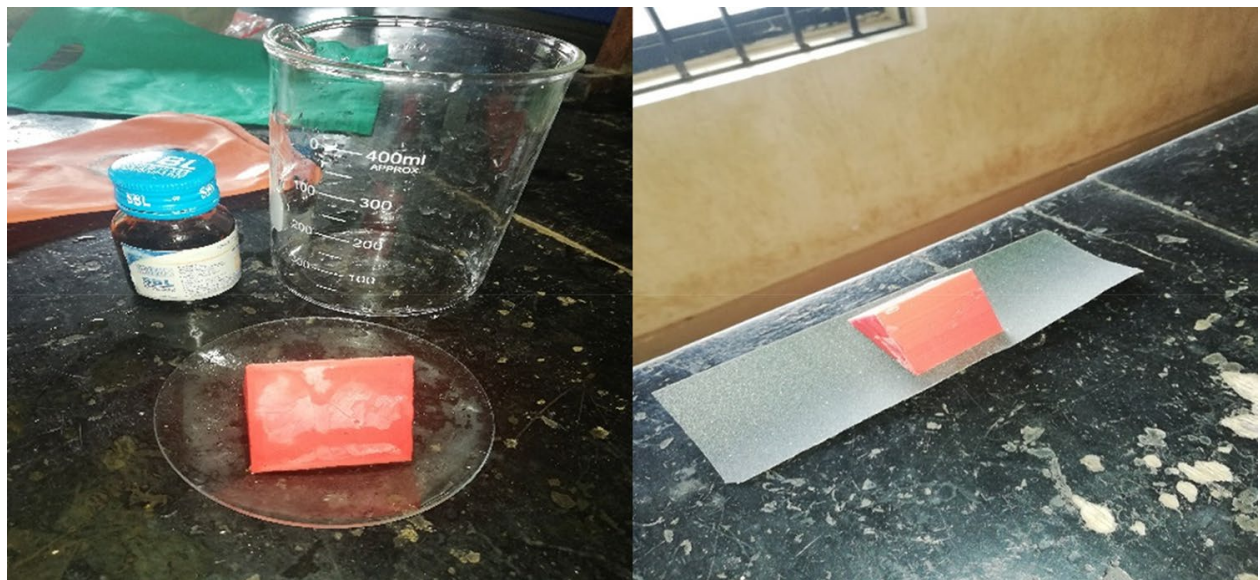
ness tester, and microstructure is detected in the microscope (Fig. 6).

\subsection{Optimization technique using Taguchi method}

In recent years, Taguchi's technique has been immensely used to optimize both process design and product design based on comprehensive experimental Investigation $[20,23]$. Using the orthogonal array, the experiment was carried out according to the experimental result, the optimum process parameter is calculated. The primary advantage of the design of experiments using Taguchi's technique includes simplification of the preliminary plan, the feasibility of the study of interaction effects among the different parameters.

After we get the result, the Taguchi method is used to optimize the process parameter. The Taguchi Method is an approach to engineering that emphasizes the roles of research and development, product design and product development in reducing the occurrence of defects and failures in products.

- Taguchi design uses orthogonal arrays to reach the optimum with the minimum trials at minimum cost.

- Orthogonality is represented as $\Sigma x_{1} x_{j}=0$, for all pair of levels, where $i$ and $j$ for high and low levels.

- In an orthogonal array, each factor has equal weights, and hence it is a balanced design.

- Advantage of orthogonality is that each factor can be evaluated independently, without influence from others, i.e. factor does not affect each other during expectation.

The design experiment steps are described briefly below.

\subsubsection{Selection of independent variables}

In our work, some critical parameters that affect surface quality are layer thickness, nozzle temperature, material flow, fill density, print speed, travel speed, infill speed, raster angle, nozzle flow, outer wall speed etc. Referring to various Taguchi based Journal the final selection is made for control factor in Taguchi experiment:

- Layer thickness (mm).

- Nozzle flow (\%).

- Print speed $(\mathrm{mm} / \mathrm{s})$.

- Nozzle temperature $\left({ }^{\circ} \mathrm{C}\right)$.

\subsubsection{Selection of the number of level settings for each variable}

See Table 7.

\subsubsection{Selection of orthogonal array}

Taguchi represent an orthogonal array as

$L_{N} S^{K}$

where $\mathrm{S}$-number of levels for each factor, $\mathrm{K}$ - maximum no. of factor whose effect can be estimated, $\mathrm{N}$-Total no of trials during experimentation.

Table 7 The level setting for each variable

\begin{tabular}{llll}
\hline Layer thickness & $0.05 \mathrm{~mm}$ & $0.15 \mathrm{~mm}$ & $0.25 \mathrm{~mm}$ \\
Nozzle flow & $60 \%$ & $80 \%$ & $100 \%$ \\
print speed & $20 \mathrm{~mm} / \mathrm{s}$ & $40 \mathrm{~mm} / \mathrm{s}$ & $60 \mathrm{~mm} / \mathrm{s}$ \\
Nozzle temperature & $200{ }^{\circ} \mathrm{C}$ & $210^{\circ} \mathrm{C}$ & $220^{\circ} \mathrm{C}$ \\
\hline
\end{tabular}

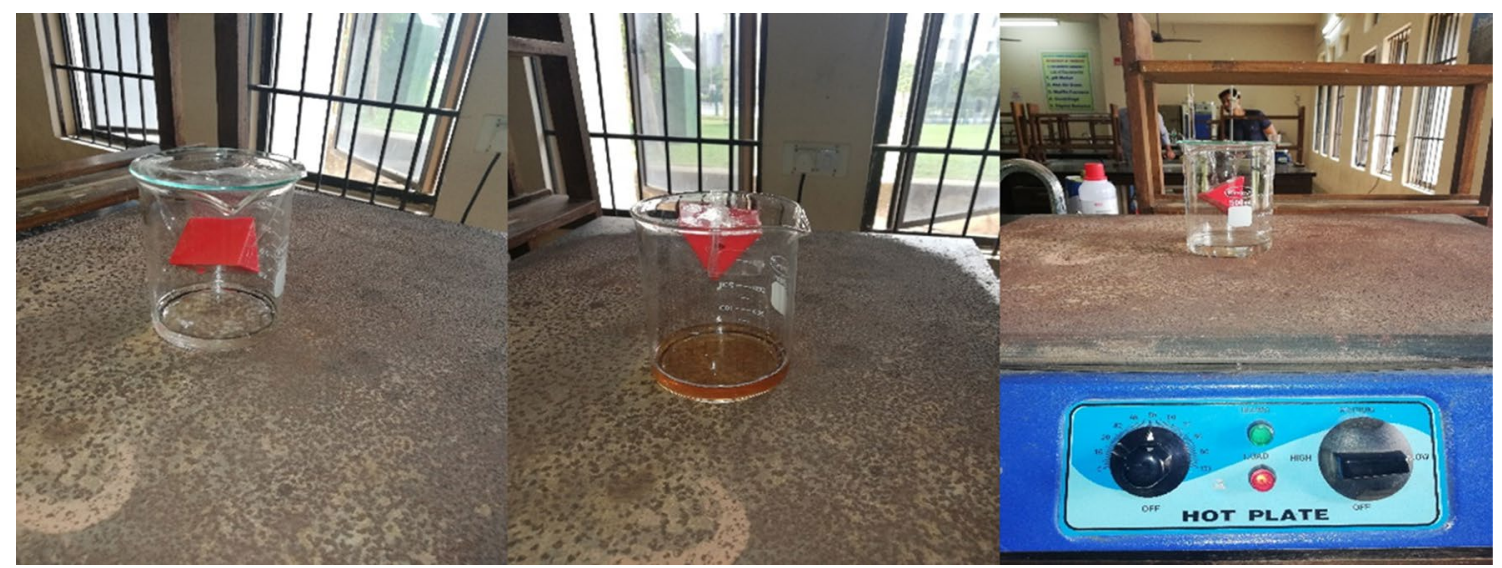

Fig. 6 Vapour treatment using dichloro methane 
In our experiment array represent as $\mathrm{L}_{9}(3)^{4}-9$ experiment runs, 4 factors with 3 levels

\subsubsection{Assigning the independent variables to each column}

After getting the 4 factors and their corresponding level values, the $L_{9}$ orthogonal array is designed, which will be used to run our experiment according to their corresponding values. Below the $L_{9}$ orthogonal array is provided with the value assigning to each column.

The $L 9$ orthogonal array is used to minimize the number of experiments to reduce repetitive output as the Taguchi L9 orthogonal array guideline suggests that conducting a minimal number of experiments to which could give full information of all factors that affect the performance parameter. The crux of the orthogonal array's method lies in choosing the level combinations of the input design variables for each experiment in our experiment there 4 different variables with 3 sets of values foes each variable. The $L_{9}$ OA represents there is no significant relation and interaction between any two factors. To understand the effect, there is no interaction should be there, but there is no interaction model assumption is valid. We did not opt for 2 or 3 repetitions of output because the output is not a part of $\mathrm{L}_{9} \mathrm{OA}$, it's just written and added to that table only 4 different variables are the part of the table where each of them is repeated for 3 times (Table 8).

Using the values of the orthogonal array table, the 8 experiments are carried out in CTTC laboratory using the same grade PLA material varying different critical parameter according to the table.

\subsubsection{Conducting the experiments}

Using the values of the orthogonal array, the 9 experiments are carried out and then stored according to their specific values so that they do not get mismatched. Here

Table $8 \mathrm{~L}_{9}$ orthogonal array

\begin{tabular}{llll}
\hline $\mathrm{A}(\mathrm{mm})$ & $\mathrm{B}(\%)$ & $\mathrm{C}(\mathrm{mm} / \mathrm{s})$ & $\mathrm{D}\left({ }^{\circ} \mathrm{C}\right)$ \\
\hline $1(0.05)$ & $1(60)$ & $1(20)$ & $1(200)$ \\
$1(0.05)$ & $2(80)$ & $2(40)$ & $2(210)$ \\
$1(0.05)$ & $3(100)$ & $3(60)$ & $3(220)$ \\
$2(0.15)$ & $1(60)$ & $2(40)$ & $3(220)$ \\
$2(0.15)$ & $2(80)$ & $3(60)$ & $1(200)$ \\
$2(0.15)$ & $3(100)$ & $1(20)$ & $2(210)$ \\
$3(0.25)$ & $1(60)$ & $3(60)$ & $2(210)$ \\
$3(0.25)$ & $2(80)$ & $1(20)$ & $3(220)$ \\
$3(0.25)$ & $3(100)$ & $2(40)$ & $1(200)$ \\
\hline
\end{tabular}

$A=$ layer thickness, $B=$ nozzle flow,$C=$ print speed, $D=$ nozzle temperature below the figure showing the specimen with their controlled parameters. The Taguchi method separate factors into two main groups: Control factor and noise factor. Control factors are those design and process parameters that can be controlled. In our study layer thickness, nozzle flow, print speed and nozzle temperature are the control factors. Noise factors are those that cannot be controlled during design and production but can be controlled during experimentation. In our study surface roughness is the noise factor which needs to be optimized using controlled factors. In additive manufacturing, there are several factors that influence surface roughness. Our main objective was to reduce the surface roughness which is caused due to various factors like vibration, angle of inclination, pressure, layer height, external geometry, density, viscosity position of an extruder, heat evacuation, platform position and mechanical properties (Fig. 7).

\subsubsection{Analyzing the data}

After producing 9 specimens with different parameter settings, the measurement of surface roughness was carried out. Then the values of surface roughness are used for calculation $\mathrm{S} / \mathrm{N}$ ratio value to find out which parameter is best or optimum for printing with best surface quality.

\subsubsection{Signal to noise ratio}

In a Taguchi designed experiment, you manipulate noise factors to force variances to occur and from the results, identify optimal control factor settings that make the process or product robust, or resistant to variation of the noise factors. There are 3 types of $\mathrm{S} / \mathrm{N}$ ratio calculation like Larger is better, Nominal is best, smaller is better. In our case, 'Smaller is better' is used because smaller the surface roughness value is better for our result.

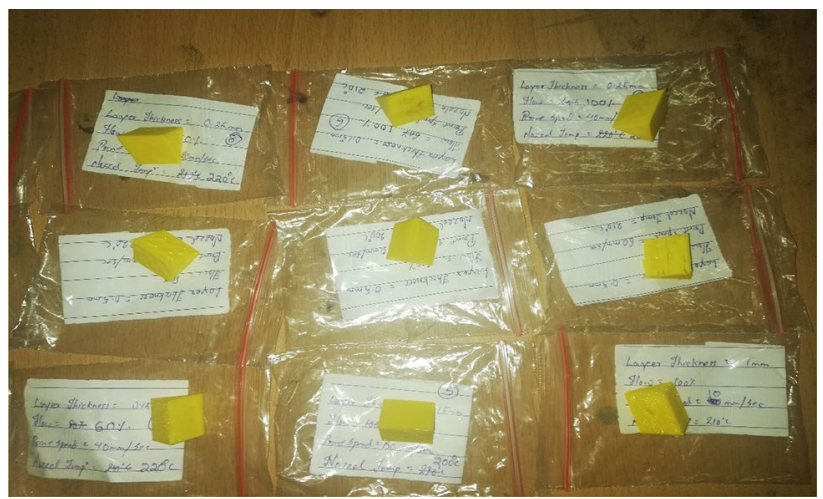

Fig. 7 Specimens after conducting Taguchi experiment 
For smaller is better $=-10 * \log (\Sigma(\mathrm{Y} 2) / \mathrm{n})$

- The signal-to-noise ratio measures how the response varies relative to the nominal or target value under different noise conditions.

- Further, Minitab is used to produce a response table as well as a graph showing the optimum parameter.

Here the surface roughness of 9 different components are measured using Taylor and Hubson Surface Roughness Tester, where each value is measured for three different times in three different places, and then the mean is calculated to obtain average surface roughness across the surface of the specimen (Fig. 8).

In our case the $\mathrm{S} / \mathrm{N}$ ratio is smaller is better so,

$\left.\mathrm{S} / \mathrm{N}=-10 * \log \left(\Sigma\left(\mathrm{Y}^{2}\right) / \mathrm{n}\right)\right)$ (For smaller is better)

Here $\left.\left(\Sigma\left(Y^{2}\right) / n\right)\right)=\operatorname{MSD}$ (mean square deviation), $\mathrm{n}=$ Nos of observations, $Y=$ the respective characteristic.

Here the surface roughness is measured in the samples could be measured as the $Y$ variable and analyzed

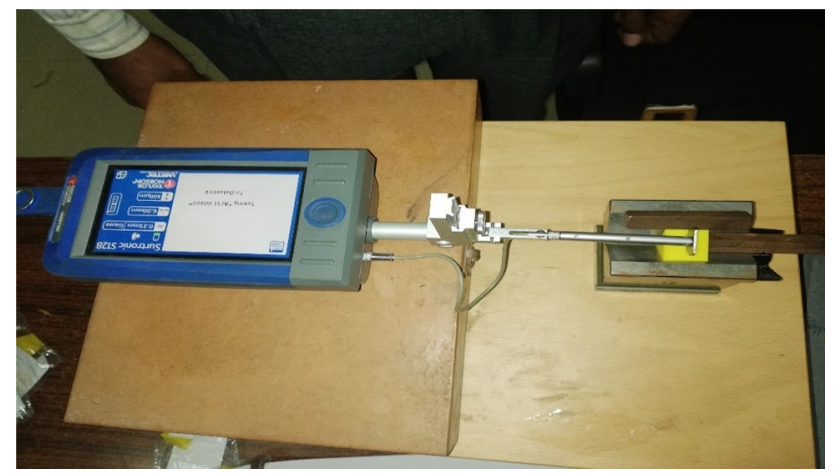

Fig. 8 Testing of specimen produced after Taguchi experiment via this $\mathrm{S} / \mathrm{N}$ ratio. The effect of the signal factors is making less since less surface roughness is the only intended or desired state of our experiment. In the equation, it states that the higher the surface roughness in the samples, the greater is the sum of the squared number of $\mathrm{Y}$ and the smaller (i.e., more negative) the $\mathrm{S} / \mathrm{N}$ ratio. So, the $\mathrm{S} / \mathrm{N}$ ratio calculation table below showing which level of the parameter is responsible for getting a higher surface finish.

From Table 9, it can be inferred that the no. $7 \mathrm{~S} / \mathrm{N}$ ratio value is highest, and no. $1 \mathrm{~S} / \mathrm{N}$ ratio value is lower. Negative $\mathrm{S} / \mathrm{N}$ ratio value means the signal is lower than noise, so the signal should be uplifted so that the value must be more significant and positive. From Table 9, the optimum parameter setting is derived and using that parameter value again; the samples are produced to go for chemical treatment for validation of our experiment.

\subsubsection{Inference}

From the above Taguchi design of experiment, we get the optimum parameter setting for printing the object with the best surface finish. Further, the MINITAB software is used to calculate the effects plots for $\mathrm{S} / \mathrm{N}$ ratio and delta/ rank value according to the response table showing which parameter is mainly responsible for producing higher surface roughness.

\subsection{Retreatment of dichloro methane with optimized sample}

Samples are produced using the values of the optimum parameter setting derived from the Taguchi design of the experiment. Then the samples are again treated with dichloromethane to know how far we go to reduce the surface roughness. The values of different post-processing technique are analyzed, and the conclusion is inferred (Fig. 9).
Table $9 \mathrm{~L}_{9}$ orthogonal arrays and calculation of signal to noise ratio

\begin{tabular}{|c|c|c|c|c|c|c|}
\hline$A(\mathrm{~mm})$ & $\mathrm{B}(\%)$ & $\mathrm{C}(\mathrm{mm} / \mathrm{s})$ & $\mathrm{D}\left({ }^{\circ} \mathrm{C}\right)$ & $\begin{array}{l}\text { Surface rough- } \\
\text { ness }(Y)(\mu \mathrm{m})\end{array}$ & $\mathrm{Y}^{2}$ & $\mathrm{~S} / \mathrm{N}$ ratio value \\
\hline $1(0.05)$ & $1(60)$ & $1(20)$ & $1(200)$ & 4.23 & 17.89 & $\left.-10 * \log \left(\Sigma\left(4.23^{2}\right) / 9\right)\right)=-2.96$ \\
\hline $1(0.05)$ & $2(80)$ & $2(40)$ & $2(210)$ & 5.53 & 30.58 & $\left.-10 * \log \left(\Sigma\left(5.53^{2}\right) / 9\right)\right)=-5.30$ \\
\hline $1(0.05)$ & $3(100)$ & $3(60)$ & $3(220)$ & 6.23 & 41.34 & $\left.-10 * \log \left(\Sigma\left(6.43^{2}\right) / 9\right)\right)=-6.61$ \\
\hline $2(0.15)$ & $1(60)$ & $2(40)$ & $3(220)$ & 8.60 & 73.96 & $\left.-10 * \log \left(\Sigma\left(8.60^{2}\right) / 9\right)\right)=-9.14$ \\
\hline $2(0.15)$ & $2(80)$ & $3(60)$ & $1(200)$ & 9.16 & 83.90 & $\left.-10 * \log \left(\Sigma\left(9.16^{2}\right) / 9\right)\right)=-9.69$ \\
\hline $2(0.15)$ & $3(100)$ & $1(20)$ & $2(210)$ & 7.43 & 55.20 & $\left.-10 * \log \left(\Sigma\left(7.43^{2}\right) / 9\right)\right)=-7.87$ \\
\hline $3(0.25)$ & $1(60)$ & $3(60)$ & $2(210)$ & 10.73 & 115.13 & $\left.-10 * \log \left(\Sigma\left(10.73^{2}\right) / 9\right)\right)=-11.06$ \\
\hline $3(0.25)$ & $2(80)$ & $1(20)$ & $3(220)$ & 8.46 & 71.57 & $\left.-10 * \log \left(\Sigma\left(8.46^{2}\right) / 9\right)\right)=-9.00$ \\
\hline $3(0.25)$ & $3(100)$ & $2(40)$ & $1(200)$ & 9.63 & 92.73 & $\left.-10 * \log \left(\Sigma\left(9.63^{2}\right) / 9\right)\right)=-10.12$ \\
\hline
\end{tabular}

$A=$ layer thickness, $B=$ nozzle flow,$C=$ print speed,$D=$ nozzle temperature 


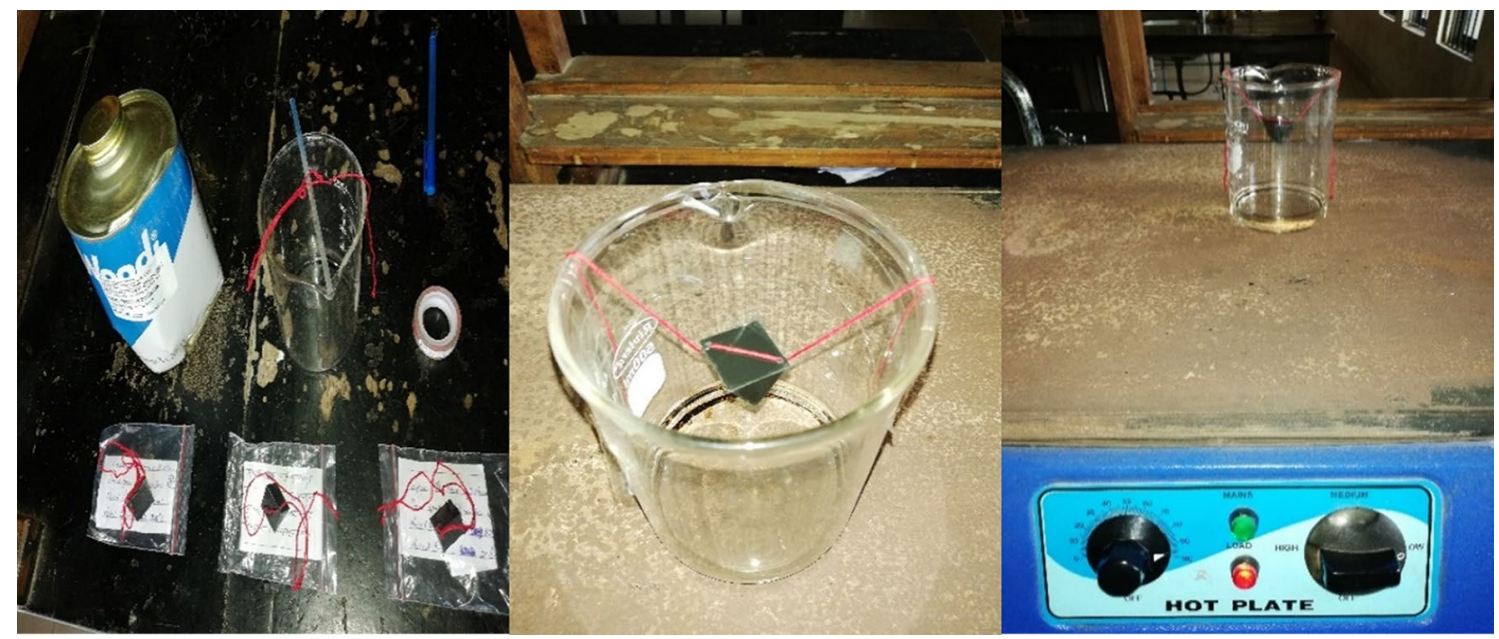

Fig. 9 Retreatment of dichloromethane with optimized sample

\subsection{Calculation of optimization parameter value using Minitab software}

Minitab software is a statistical tool that is used for quality improvement using robust data analysis. Minitab allows the user to create, manipulate and restructure data, produce a variety of graphs from simple charts to detailed diagrams and perform comprehensive statistical analysis. In our experiment, Minitab is used to determine the optimized value and the $\mathrm{S} / \mathrm{N}$ ratio graphs to determine the delta and rank value which allow us to determine which factor is responsible for producing higher surface roughness value [19]. The results and graphs are described in Sect. 3.2 here only the Investigation using the software are described. The values derived from the Taguchi design of the experiment is put in the software in excel format. The Taguchi design of experiment under the DOE tab is used to determine the results and graphs for various responsible factors.

\section{Experimental results}

ANOVA analysis is not suggested in our study because it will more complicate our experiment. After all, the study is moreover a combination of chemical experiments and Taguchi technique. Our main objective is to enhance the surface finish of FDM parts by using the post-processing and optimization technique, due to our desired result was achieved after using Taguchi method of design and chemical post-processing, we never designed an ANOVA analysis which is not required in our opinion.

\subsection{Surface roughness and microstructure detection}

Table 10 shows different post-processing results along with microstructure and surface roughness value. We can notice the microstructure of various experiment starting from raw sample to vapour chemical smoothing using optimized value; the layer lines are gradually reduced. In the sample where no post-processing is used, we can see that the layer lines are visible. But after the chemical treatment, the layer lines get dissolve. The best result comes from dichloromethane, where the other chemicals are failed to dissolve the PLA material in comparison to dichloromethane.

Further, the sandpaper is used along with chemical treatment where we had noticed a small drop in surface roughness value, but the vinyl polisher is doing better work than sandpaper. Vapour chemical smoothing process reduced the roughness value up to $0.40 \mu \mathrm{m}$ which is very less from the initial value.

Taguchi design of an experiment is used to optimize the critical parameter where the result came after optimization is $4.00 \mu \mathrm{m}$. And after vapour chemical smoothing process over the optimized value, the surface roughness value reduced to $0.2 \mu \mathrm{m}$, which is very less.

\subsection{Optimization using Minitab software}

The data from the Taguchi design of the experiment is put in the Minitab software, and the optimization is done using the DOE function under its menu. The result of the software is described in Fig. 10. Signal to noise ratio is calculated on the basis of smaller is better. From 
Table 10 Surface roughness and microstructure detection of samples prepared

\begin{tabular}{|c|c|c|c|c|}
\hline Post processing technique used & $\begin{array}{l}\text { Chemical/ } \\
\text { machine/param- } \\
\text { eter used }\end{array}$ & Method & Surface roughness & Micro structure \\
\hline $\begin{array}{l}\text { No post-processing technique } \\
\text { is used }\end{array}$ & Not chemical used & $\begin{array}{l}\text { Directly produced from FDM } \\
\text { machine }\end{array}$ & $12.0 \mu \mathrm{m}$ & \\
\hline Chemical treatment & Acetone & $\begin{array}{l}\text { 1. Dipping } \\
\text { 2. Spraying }\end{array}$ & $\begin{array}{l}9.80 \mu \mathrm{m} \\
10.30 \mu \mathrm{m}\end{array}$ & \\
\hline Chemical treatment & Ethyl acetate & $\begin{array}{l}\text { 1. Dipping } \\
\text { 2. Spraying }\end{array}$ & $\begin{array}{l}8.90 \mu \mathrm{m} \\
8.70 \mu \mathrm{m}\end{array}$ & \\
\hline Chemical treatment & Isopropyl alcohol & $\begin{array}{l}\text { 1. Dipping } \\
\text { 2. Spraying }\end{array}$ & $\begin{array}{l}11.20 \mu \mathrm{m} \\
10.10 \mu \mathrm{m}\end{array}$ & \\
\hline Chemical treatment & Sodium hydroxide & $\begin{array}{l}\text { 1. Dipping } \\
\text { 2. Spraying }\end{array}$ & $\begin{array}{l}3.40 \mu \mathrm{m} \\
2.50 \mu \mathrm{m}\end{array}$ & \\
\hline Chemical treatment & Dichloromethane & $\begin{array}{l}\text { 1. Dipping } \\
\text { 2. Spraying }\end{array}$ & $\begin{array}{l}1.10 \mu \mathrm{m} \\
1.00 \mu \mathrm{m}\end{array}$ & \\
\hline Chemical Treatment & Tetrahydrofuran & $\begin{array}{l}\text { 1. Dipping } \\
\text { 2. Spraying }\end{array}$ & $\begin{array}{l}1.80 \mu \mathrm{m} \\
2.10 \mu \mathrm{m}\end{array}$ & \\
\hline $\begin{array}{l}\text { Chemical treatment along with } \\
\text { sandpaper }\end{array}$ & Dichloromethane & $\begin{array}{l}\text { 1. } 500 \text { micron } \\
\text { 2. } 1000 \text { micron } \\
\text { 3. } 1500 \text { micron }\end{array}$ & $\begin{array}{l}1.50 \mu \mathrm{m} \\
1.10 \mu \mathrm{m} \\
0.80 \mu \mathrm{m}\end{array}$ & \\
\hline
\end{tabular}


Table 10 (continued)

\begin{tabular}{|c|c|c|c|c|}
\hline Post processing technique used & $\begin{array}{l}\text { Chemical/ } \\
\text { machine/param- } \\
\text { eter used }\end{array}$ & Method & Surface roughness & Micro structure \\
\hline $\begin{array}{l}\text { Chemical treatment with the } \\
\text { transparent polisher }\end{array}$ & Dichloromethane & $\begin{array}{l}100 \% \text { conc. DCM and vinyl } \\
\text { polisher }\end{array}$ & $0.70 \mu \mathrm{m}$ & \\
\hline Vapour chemical smoothing & Dichloromethane & Hot plate at $50-60^{\circ} \mathrm{C}$ & $0.40 \mu \mathrm{m}$ & \\
\hline $\begin{array}{l}\text { Optimization technique using } \\
\text { Taguchi method }\end{array}$ & $\begin{array}{l}\text { Orthogonal } \\
\text { array, S/N ratio, } \\
\text { Minitab software }\end{array}$ & $\begin{array}{l}\text { 1. Layer thickness } \\
\text { 2. Print speed } \\
\text { 3. Nozzle flow } \\
\text { 4. Nozzle temp }\end{array}$ & $4.00 \mu \mathrm{m}$ & \\
\hline $\begin{array}{l}\text { Vapour chemical smoothing } \\
\text { using the optimized value }\end{array}$ & Dichloromethane & $\begin{array}{l}\text { Hot plate at } 60^{\circ} \mathrm{C} \text {, vapour treat- } \\
\text { ment }\end{array}$ & $0.2 \mu \mathrm{m}$ & \\
\hline
\end{tabular}

Fig. $10 \mathrm{~S} / \mathrm{N}$ ratio value versus critical parameter
Main Effects Plot for SN ratios Data Means

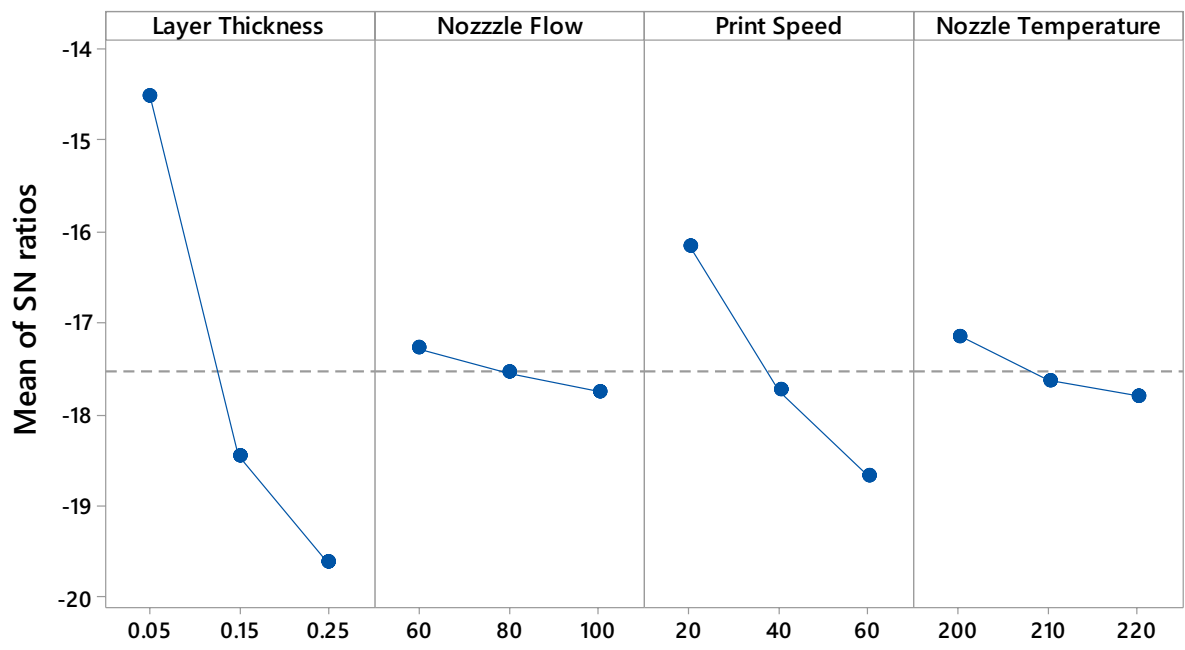

Signal-to-noise: Smaller is better
Fig. 10, it clear that the $\mathrm{S} / \mathrm{N}$ ratio is decreasing with increase in critical parameters. So using layer thickness as the smaller value, we can get the higher surface finish. The lower nozzle flow leads to higher surface finish. The lower print speed leads to higher surface finish. By using a lower temperature, we can achieve a higher surface finish.

Table 11 is also showing delta and rank value which provide adequate information to determine which parameter is affecting crucially to surface finish. The higher value of 
Table 11 Response table

\begin{tabular}{lllll}
\hline Level & Layer thickness & Nozzle flow & Print speed & $\begin{array}{l}\text { Nozzle } \\
\text { tempera- } \\
\text { ture }\end{array}$ \\
\hline $\begin{array}{l}\text { Response table for signal to noise ratios } \\
\text { Smaller is better }\end{array}$ & & \\
1 & -14.52 & -17.28 & -16.16 & -17.15 \\
2 & -18.45 & -17.55 & -17.74 & -17.63 \\
3 & -19.61 & -17.75 & -18.67 & -17.80 \\
Delta & 5.10 & 0.48 & 2.51 & 0.65 \\
Rank & 1 & 4 & 2 & 3 \\
\hline
\end{tabular}

delta leads to a higher rank and higher rank, pointing to the parameter that affects the function crucially. In our experiment, according to the response table, we can say that layer thickness is affecting the surface finish very crucially, and after layer thickness, print speed is highly responsible. The nozzle flow and nozzle temperature come after print speed in affecting the surface finish.

\section{Conclusions}

This study reports an experimental model for the analysis of the effect of critical parameters on surface roughness of PLA Object Produced by Fused Deposition Method. And various post-processing techniques have been performed on the PLA Object to reduce the surface roughness. Taguchi's technique has been used to optimize process parameters to reduce surface roughness. Vapour treatment with dichloromethane chemical treatment as a post-processing technique has been performed on PLA object produced after optimizing process parameters. The following conclusions are drawn from this study:

1. Dichloromethane was found to be useful in dissolving the layer lines which generally present in FDM generated parts. It can significantly reduce the surface roughness of very complex parts quickly and effectively.

2. Surface roughness is mostly influenced by layer thickness. Optimized process parameter produced the PLA object with a greater surface finish.

3. Vapour treatment, along with dichloromethane chemical treatment reduces the surface roughness of PLA object to $0.2 \mu \mathrm{m}$.

In future, Response surface methodology and ANOVA analysis can be done in our experiment. Using the Taguchi method, the short production time and surface texture by optimizing the process parameter can also be predicted.

\section{Compliance with ethical standards}

Conflict of interest The authors declare that they have no conflict of interest.

\section{References}

1. JTEC/WTEC panel report on rapid prototyping in Europe and Japan pg.24

2. NSF JTEC/WTEC panel report-RPA (2016) Archived copy (PDF). Archived from the original (PDF) on 2017-08-30. Retrieved 28 Dec 2016

3. Gupta P, Yadav A, Kumar A, Sinha N (2019) Modelling of heat transfer in powder bed based additive manufacturing process using lattice Boltzmann method. In: Kumar LJ, Pandey PM, Wimpenny DI (eds) 3D printing and additive manufacturing technologies. Springer, Singapore, pp 83-94

4. Yadav A, Ghosh A, Kumar A (2019) Thermal transport phenomena in multi-layer deposition using arc welding process. In: Kumar LJ, Pandey PM, Wimpenny DI (eds) 3D printing and additive manufacturing technologies. Springer, Singapore, pp $15-27$

5. Ramya A, Vanapalli SL (2016) 3D printing technologies in various applications. Int J Mech Eng Technol 7(3):396-409

6. Dandgaval OJAS, Bichkar PRANIT (2016) Rapid prototyping technology-study of fused deposition modeling technique. Int J Mech Prod Eng 4(4):44-47

7. Wong KV, Hernandez A (2012) A review of additive manufacturing. ISRN Mechanical Engineering 2012

8. Sukindar NA et al (2017) Optimization of the parameters for surface quality of the open-source 3D printing. J Mech Eng 3(1):33-43

9. Alsoufi MS, Elsayed AE (2017) How surface roughness performance of printed parts manufactured by desktop FDM 3D printer with PLA + is influenced by measuring direction. Am J Mech Eng 5(5):211-222

10. Sinha DK, Kumar S, Kumar A, Yadav A (2018) Optimization of process parameters in continuous extrusion of aluminium alloy. In: 2018 International conference on computational and characterization techniques in engineering and sciences (CCTES). IEEE, pp 246-251

11. Pandey N, Singh R, Pant P, Yadav A (2018) Development of mathematical model for material removal and surface roughness in electrolytic magnetic abrasive finishing process. In: IOP conference series: materials science and engineering. IOP Publishing, vol 404(1), p 012053

12. Moayyedian M, Derakhshandeh JF, Said S (2018) Experimental investigations of significant parameters of strain measurement employing Taguchi method. SN Appl Sci 1(1):92

13. Garg A, Bhattacharya A, Batish A (2016) On surface finish and dimensional accuracy of FDM parts after cold vapor treatment. Mater Manuf Process 31(4):522-529

14. Singh R et al (2017) Investigation for surface finish improvement of FDM parts by vapor smoothing process. Compos Part B Eng 111:228-234

15. Jin $Y$ et al (2017) Modeling of the chemical finishing process for polylactic acid parts in fused deposition modeling and investigation of its tensile properties. J Mater Process Technol 240:233-239 
16. Surange VG, Gharat PV (2016) 3D printing process using fused deposition modelling (FDM). Int Res J Eng Technol (IRJET) 3(3):1403-1406

17. Venkatasubbareddy OY, Siddikali P, Mahammad Saleem S (2016) Improving the dimensional accuracy and surface roughness of FDM parts using optimization techniques. IOSR J Mech Civ Eng pp 18-22. E-ISSN: 2278-1684, p-ISSN: 2320-334X

18. Anitha $R$, Arunachalam $S$, Radhakrishnan $P$ (2001) Critical parameter influencing the quality of prototypes in fused deposition modelling. J Mater Process Technol 118:385-388

19. Garlotta Donald (2001) A literature review of poly(lactic acid). J Polym Environ 9(2):63-84

20. Hafsa MN et al (2014) Evaluation of FDM pattern with ABS and PLA material. In: Ismail AE, Nor NHM, Mohd Ali MF, Ahmad R, Masood I, Mohd Tobi AL, Abdul Ghafir MF, Muhammad M, Wahab MS, Zain BAM, Siswanto WA (eds) Applied mechanics and materials. Trans Tech Publications, vol 465
21. Cuiffo MA et al (2017) Impact of the fused deposition (FDM) printing process on polylactic acid (PLA) chemistry and structure. Appl Sci 7(6):579

22. Doli B et al (2017) Analysis of fused deposition modeling process for additive manufacturing of Abs parts. In: Proceedings of 10 International conference on precision, meso, micro and nano engineering (COPEN 10) December 07-09 2017, Indian Instityute of Technology Madras, Chennai, India

23. Mohamed OA, Masood SH, Bhowmik JL (2015) Optimization of fused deposition modelling process parameters: a review of current research and future prospects. Adv Manuf 3(1):42-53

Publisher's Note Springer Nature remains neutral with regard to jurisdictional claims in published maps and institutional affiliations. 